\title{
(Non-)factive (non-)islands and meaning-based approaches *
}

\author{
Kajsa Djärv \\ University of Konstanz
}

\author{
Maribel Romero \\ University of Konstanz
}

\begin{abstract}
A key question in the literature on factive Weak Islands has been whether the effect is syntactic or semantic. Since Szabolcsi \& Zwarts (1993), a key argument for the semantic nature of Weak Islands is the observation that the effect requires not just factivity, but also that the property described by the embedded clause is non-iterable with respect to the extracted argument (uniqueness). We present two caveats concerning the notion of factivity needed in meaning-based approaches. First, we present novel data on factive non-islands showing that certain lexically factive verbs do not (always) lead to islandhood when combined with uniqueness. Second, recalling data from Cattell (1978), we argue that certain non-factive islands can be captured by the same meaning-based explanation. The emerging picture is that lexical factivity of the embedding verb is neither necessary nor sufficient to induce weak islands in combination with uniqueness; rather, what matters is whether or not there is a contextual entailment, pragmatic or lexical, that the complement proposition is true.
\end{abstract}

Keywords: weak islands, factive islands, response stance verbs, presupposition, extraction

\section{Introduction}

Since the seminal work by Ross (1984), it is known that extraction is constrained in certain configurations called 'islands'. While strong islands always block extraction regardless of what kind of phrase is extracted, weak islands have been observed to allow extraction in some cases but not in others, as in (1)-(3):

(1) Weak island: Whether-island

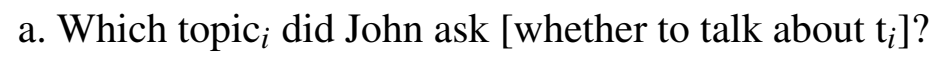

b. * How did John ask [whether to behave $\mathrm{t}_{i}$ ]?

c. * Why did John ask [whether Mary complained $\mathrm{t}_{i}$ ]?

* We would like to thank our colleagues at the University of Konstanz; especially Anna Czypionka, Felix Frühauf, and David Krassnig, as well as the audiences at SALT 31, for helpful feedback and comments. We thank the DFG (project RO 4247/3-2) for financial support for this work. 
(Non-)factive (non-)islands and meaning-based approaches

(2) Weak island: Negative island

a. I asked which topic ${ }_{i}$ John didn't talk about $t_{i}$ ?

b. * I asked how John didn't behave $t_{i}$ ?

c. * I asked why John didn't [complain $t_{i}$ ?

(3) Weak island: Factive island

a. Which topic ${ }_{i}$ do you regret [that John talk about $\mathrm{t}_{i}$ ]?

b. *? How do you regret [that John behaved $t_{i}$ ?

c. * Why do you regret [that Mary complained $\mathrm{t}_{i}$ ?

Weak islands may be induced by different elements, e.g. by a whether-question in (1), by negation in (2) and by the complement of a factive attitude verb in (3). ${ }^{1}$ In this paper, we concentrate on so-called 'factive' islands like (3). To see the effect of factivity in closer detail, compare the (a)-variants below containing a lexically factive like know, which selectively blocks extraction, with the (b)-variants containing a non-factive verb like think, which freely allows extraction:

a. To which student does John know [that Mary showed this letter $\left.t_{i}\right]$ ? [+fact]

b. To which student does John think [that Mary showed this letter $t_{i}$ ]? [-fact]
a. *? How ${ }_{i}$ does Max know [that Alice went to San Francisco $\left.t_{i}\right]$ ? [+fact]
b. How $i$ does Max think [that Alice went to San Francisco t ${ }_{i}$ ? [-fact]
a. * Why $_{i}$ does Max know [that Alice insulted Pat $\left.\mathrm{t}_{i}\right]$ ? [+fact]
b. Why ${ }_{i}$ does Max think [that Alice insulted Pat $t_{i}$ ? $\quad[-$ fact $]$

In early work, the contrast among different phrases extracted out of a weak island was attributed to their argumental status: argument $w h$-phrases can be extracted, e.g. out of the factive island in (4a), whereas adjunct $w h$-phrases cannot, as seen in (5a)-(6a) (Huang 1982; Lasnik \& Saito 1984, 1994). The explanations sought were rooted in syntactic differences between arguments and adjuncts.

However, later work noted that the relevant distinction is more nuanced. Szabolcsi \& Zwarts (1993) observed that argument extraction out of the complement of a (lexically) factive verb leads to ungrammaticality in certain cases too, namely, when the event described in the embedded clause is non-iterable with respect to the extracted argument. The contrast is illustrated in (7): Extraction is grammatical in (7a), where the embedded property [ $\lambda$ x.you have shown this letter to $x$ ] may be iterated over several individuals, whereas extraction leads to ungrammaticality in ( $7 b$ ), where the embedded property [ $\lambda$ x.you have gotten this letter from $\mathrm{x}$ ] applies uniquely, i.e., cannot hold of more than one individual:

1 See Szabolcsi (2006) for an overview. 
a. To whom $_{i}$ do you regret [having shown this letter $t_{i}$ ]

b. $*$ From $w_{h o m}$ do you regret [having gotten this letter $t_{i}$ ?

Generalizing the pattern, Oshima (2007) argued that extraction of why always leads to an embedded unique, non-iterable property, thus rendering extraction ungrammatical. Similarly, he argued that extraction of how tends to be interpreted as leading to an embedded unique property as well, with the same ungrammatical result.

These and other observations have led to a new research line of meaning-based explanations of factive islands (Szabolcsi \& Zwarts 1993, 1997; Abrusán 2011; Oshima 2007; Schwarz \& Simonenko 2018; Schwarz, Oshima \& Simonenko 2019: a.o.). The goal of the present paper is to present two caveats concerning the notion of factivity needed in meaning-based approaches. We illustrate these two caveats for Schwarz \& Simonenko (2018)'s approach, but they in principle apply to other meaning-based approaches capitalizing on factivity. First, we present novel data on factive non-islands showing that certain lexically factive verbs do not (always) lead to islandhood when combined with uniqueness. Second, recalling data from Cattell (1978), we argue that certain non-factive islands should receive the same meaning-based explanation. The emerging picture is that lexical factivity of the embedding verb is neither necessary nor sufficient to induce weak islandhood in combination with uniqueness; rather, what matters is whether or not there is a contextual entailment, pragmatic or lexical, that the complement proposition is true.

The remainder of this paper is organized as follows. Section 2 outlines Schwarz \& Simonenko (2018)'s meaning-based analysis of factive islands. Section 3 presents the two challenges: factive non-islands and non-factive islands. In section 4, we show how these two challenges are overcome once lexical factivity is replaced by the more flexible notion of contextual entailment. In section 5, the meaning-based approach is extended to cases involving other presupposition triggers. Section 6 concludes.

\section{The meaning-based approach by Schwarz \& Simonenko (2018)}

Schwarz \& Simonenko (2018) derive the selective ungrammaticality of factive islands from the consequences that the combination of factivity and uniqueness has for the felicity conditions of questions. The crucial contrast is recapitulated in (8). If the embedding verb is factive -e.g. know- and the "gapped" property resulting from extraction is unique -e.g. [ $\lambda \mathrm{x} . \lambda \mathrm{w}$. Caesar was murdered in $\mathrm{x}$ in $\mathrm{w}]$ can be true of at most one location at any given $w-$, the sentence in ungrammatical, as in (8a). If factitivy is removed -e.g. by using non-factive think-, the sentence is grammatical, 
(Non-)factive (non-)islands and meaning-based approaches

as in (8b). Alternatively, if the embedded gapped property is non-unique, as in (8c), the result is also grammatical.

Schwarz, Oshima \& Simonenko (2019: 529-530)

a. ${ }^{*}$ Where ${ }_{i}$ did they know that Caesar was murdered $t_{i}$ ? [+fact,+uni]

b. Where ${ }_{i}$ did they think that Caesar was murdered $t_{i}$ ? [-fact,+uni]

c. Where ${ }_{i}$ did they know that Caesar had sent troops $t_{i}$ ? [+fact,-uni]

Let us consider first what effect the combination of factivity and uniqueness has on the context set $\mathbf{c}$ that serves as input to the question. Take $\mathbf{R}$ to stand for the property in the restrictor of the wh-phrase, $\mathbf{S}$ to be the property in the nuclear scope and $\mathbf{P}$ to be the embedded gapped property, as exemplified in (9). Given that the gapped clause entails uniqueness of $\mathbf{P}$ and that the embedding verb, being factive, presupposes the truth of its complement clause, the matrix IP as a whole presupposes uniqueness of $\mathbf{P}$. This is then combined with a Hamblin/Karttunen-style semantics for questions, whereby a question denotes the set of its possible answers (Hamblin 1973; Karttunen 1977). Each possible answer will presuppose uniqueness of $\mathbf{P}$, as sketched in the question intension schema (9d). As a consequence, the question as a whole will presuppose uniqueness of $\mathbf{P}$, leading to the result in (10): For each world $\mathrm{w}$ in the context set $\mathrm{c}$, there is at most one proposition in the question's denotation whose presupposition is true at $\mathrm{w}$.

(9) * Where / In which place did they know that Caesar was murdered?

a. R: $\lambda \mathrm{x} . \lambda \mathrm{w} . \mathrm{x}$ is a place in $\mathrm{w}$

b. S: $\lambda \mathrm{x} . \lambda \mathrm{w}$ : Caesar was murdered in $\mathrm{x}$ in $\mathrm{w}$. they believe that Caesar was murdered in $\mathrm{x}$ in $\mathrm{w}$

c. P: $\lambda \mathrm{x} . \lambda \mathrm{w}$. Caesar was murdered in $\mathrm{x}$ in $\mathrm{w}$

d. $\lambda$ w. $\left\{\lambda w^{\prime}: \mathbf{P}(\mathrm{x})\left(w^{\prime}\right) . \mathbf{S}(\mathrm{x})\left(\mathrm{w}^{\prime}\right) \mid \mathbf{R}(\mathrm{x})(\mathrm{w})\right\}$

(10) Consequence of factivity plus uniqueness:

$\mathrm{c} \subseteq\{\mathrm{w}:|\{\mathrm{p}: \mathrm{p} \in \mathrm{Q}(\mathrm{w}) \wedge \mathrm{w} \in \operatorname{dom}(\mathrm{p})\}| \leq 1\}$

We turn now to two felicity conditions for questions invoked in Schwarz \& Simonenko (2018)'s account. The first one, dubbed Answerability Condition and stated in (11), requires that the context set $\mathrm{c}$ be consistent with the question having an answer $\mathrm{p}$ which is informative -i.e., not yet entailed by c ( $\$$ $\$$ ) - and whose presupposition is met (c $\subseteq \operatorname{dom}(\mathrm{p}))$. The second felicity condition is an existence presupposition argued to arise in wh-questions (Dayal 1996; Abusch 2010): A whquestion presupposes that there is at least one true answer in the denoted Hamblin set, as in (12): 
(11) Felicity condition 1: Answerability Condition A question $Q$ is felicitous in a context c only if $\exists \mathrm{p}[\exists \mathrm{w}[\mathrm{w} \in \mathrm{c} \wedge \mathrm{p} \in \mathrm{Q}(\mathrm{w})] \wedge \mathrm{c} \subseteq \operatorname{dom}(\mathrm{p}) \wedge \mathrm{c} \nsubseteq \mathrm{p}]$

(12) Felicity condition 2: $\exists$-presupposition

A question $\mathrm{Q}$ is felicitous in a context c only if $\mathrm{c} \subseteq\{\mathrm{w}: \exists \mathrm{p}[\mathrm{p} \in \mathrm{Q}(\mathrm{w}) \wedge \mathrm{p}(\mathrm{w})]\}$

Schwarz \& Simonenko (2018) show that, in a question involving factivity and uniqueness, these two felicity conditions lead to contradictory demands, so that there is no possible context set $\mathrm{c}$ that satisfies them both. To see this, consider the three toy context sets below, with the extension of the properties $\mathbf{R}, \mathbf{S}$ and $\mathbf{P}$ from (9) specified for each $w$ in the context set and where there are only two locations altogether, namely, Rome (r) and Alexandria (a). In the case of (13), the context set c contains two worlds: one in which Caesar was murdered in Rome and they believe so, and one in which Caesar was murdered in Alexandria and they equally believe so. This context set c violates the presupposition part of the Answerability Condition (11), since there is no $\mathrm{p}$ in the denotation $\mathrm{Q}(\mathrm{w})$ under some $\mathrm{w}$ in $\mathrm{c}$ such that the presupposition of that $\mathrm{p}$ is entailed by the (entire) context set.

$$
\mathrm{c}=\left\{\begin{array}{l}
\mathrm{W}_{\mathbf{R}}:\{\mathrm{r}, \mathrm{a}\}, \mathbf{P}:\{\mathrm{r}\}, \mathrm{S}:\{\mathrm{r}\} \\
\mathrm{W}_{\mathbf{R}:\{\mathrm{r}, \mathrm{a}\}, \mathbf{P}:\{\mathrm{a}\},}, \mathbf{S}:\{\mathrm{a}\}
\end{array}\right\}
$$

A similar fate awaits context set (14). Here, it is already settled in the context set that Caesar was murdered in Rome and that they believe so. The informativity part of the Answerability Condition fails: Though there is a possible answer $\mathrm{p}$ whose presupposition is entailed by the (entire) $\mathrm{c}$-namely, $[\lambda \mathrm{w}$ : Caesar was murdered in $\mathrm{r}$ in w. they believe that Caesar was murdered in $\mathrm{r}$ in $\mathrm{w}]-, \mathrm{p}$ itself is entailed by $\mathrm{c}$ and thus it is not informative.

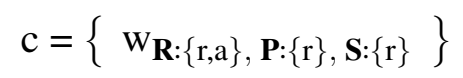

The final case, in (15), involves a context set that entails that Caesar was murdered in Rome but leaves open whether they believe so or they do not believe of any particular place $x$ that Caesar was murdered in $x$. This time, the Answerability Condition is fully satisfied, since we can find a possible answer-again, [ $\lambda \mathrm{w}$ : Caesar was murdered in $r$ in $w$. they believe that Caesar was murdered in $r$ in $w$ ]- whose presupposition is satisfied by the (entire) context set and whose at-issue contribution is still informative. However, the Existence Presupposition is not met, since c-via the world listed first- is consistent with there being no true answer in $\mathrm{Q}(\mathrm{w})$.

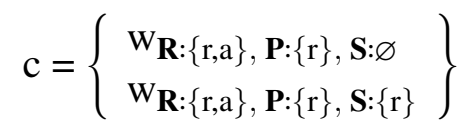


(Non-)factive (non-)islands and meaning-based approaches

In the following section, we discuss two potential challenges for a meaningdriven account to factive islands.

\section{Two potential challenges}

\subsection{Factive non-islands}

We start by observing that there are cases where extraction is possible in environments that are strictly +Factive and +Unique, as shown in (16).

(16) Big news! Archaeologists reveal new facts about the life and death of Caesar

a. So tell me - where did they \{discover, learn that Caesar was killed?

b. Hey - do you know who they just found out that Caesar was killed by?

Here, it looks like the meaning-based approach is too strong, in that it seems to over-generate weak island contexts. At first glance, what seems to be going on in these examples is that the presuppositional part (c $\subseteq \operatorname{dom}(\mathrm{p}))$ of the Answerability Condition (11) is not met; clearly, the reason for asking these questions is that the context does not entail, for any specific location $\mathrm{x}$, that Caesar was killed in that location $\mathrm{x}$.

Does that then mean that the Answerability Condition is not in fact a felicity condition on questions? Not necessarily: it seems like the principle is generally motivated. For instance, an information-seeking question like (17) seems to require that the context entails (not just that one but) that all of the individuals satisfying the restrictor property $\mathbf{R}$-here, the property 'being one of our five zebras'- also satisfy the property 'being female' arising from the presupposition triggers herself and her (Schlenker 2008; Theiler 2021):

(17) Which of our five zebras let herself out of her enclosure?

Instead, we will argue, in section 4.1 that the explanation for why the questions in (16) are acceptable lies in the observation that cognitive factives like discover and find out more generally allow for parenthetical uses, in which $\mathrm{p}$ is not treated as part of the common ground (see, among others, Urmson 1952; Simons 2007, and Djärv 2019, for discussion):

(18) Big news! Archaeologists reveal new facts about the life and death of Caesar. They just \{found out, discovered, learned $\}$ that Caesar was actually killed in the Theatre of Pompey! (And not in the regular Senate Building.)

In such cases, the speaker does not treat $\mathrm{p}$ as being part of the common ground; rather, the function of an utterance like that in (18) is to add the proposition that 
Caesar was killed in the Theatre of Pompey to the common ground, as discourse new information. Nevertheless, as shown in (19), the sentence still differs from its corresponding non-factive sentence, in that $\mathrm{p}$ is still entailed:

(19) Big news! Archaeologists reveal new facts about the life and death of Caesar.

a. They just \{found out, discovered, learned \} that Caesar was actually killed in the Theatre of Pompey. (\#Though he was in fact killed in the regular Senate Building.)

b. They \{think, are saying that Caesar was actually killed in the Theatre of Pompey. (Though he was in fact killed in the regular Senate Building.)

The same is true for the corresponding question. In asking (16), the speaker still assumes that the location where the archaeologists discovered that Caesar was killed is the place where Caesar was in fact killed (in the evaluation world). This is unlike the corresponding question involving a non-factive verb (20), which also has this type of evidential use - though a weaker one than the factive question: here, the speaker does not assume that the location where the archaeologists think that Caesar was killed is necessarily the place where Caesar was killed.

(20) Big news! Archaeologists reveal new facts about the life and death of Caesar. So tell me - where do they \{think, believe $\}$ that Caesar was killed?

It is well-documented that emotive factives like regret and appreciate do not generally allow for the kinds of parenthetical uses illustrated in (18), but impose a stronger requirement that $\mathrm{p}$ be common ground (see Djärv 2019 for experimental results corroborating this contrast between cognitive and emotive factives).

(21) Big news! Archaeologists reveal new facts about the life and death of Caesar. \#They $\{$ resent, appreciate, are happy $\}$ that Caesar was actually killed in the Theatre of Pompey.

We thus expect that questions involving emotive factives should not be rescued by the kinds of evidential questions illustrated in (16); a prediction which is borne out:

(22) Big news! Archaeologists reveal new facts about the life and death of Caesar.

\#So tell me - where do they \{regret, appreciate $\}$ that Caesar was killed?

To summarize this section, questions containing a factive verb can 'escape' meaning-driven ungrammaticality in (at least) two ways: either via non-uniqueness, as in (8c), or via an 'evidential question' (if the factive verb permits), as in (16). In the following section, we discuss a second caveat regarding the precise notion of factivity that is relevant to weak island effects: non-factive (attitude) islands. We also include a brief discussion of how previous proposals have dealt with these cases. 
(Non-)factive (non-)islands and meaning-based approaches

\subsection{Non-factive islands}

A perhaps more serious challenge for the type of meaning-based approach discussed here is that it appears to under-generate weak island environments. Since Cattell (1978), it has been observed that factive verbs are only one type of attitude verb that gives rise to weak island effects. As illustrated in (23), Cattell's (1978) class of response stance verbs (i.e. non-factive verbs like admit, accept, deny) are also weak island inducers:

Szabolcsi (2006: 508)

How $_{i}$ did you $\{$ think, *realize, *accept $\}$ that he behaved $t_{i}$ ?

Unlike realize, discover, know and find out, etc., accept is not lexically factive, as illustrated by (24): ${ }^{2}$

(24) I don't believe [that Caesar was killed in the Temple of Jupiter $]_{i}$, but I will accept it ${ }_{i}$ for the purpose of this conversation.

This observation has lead a number of researchers, including Melvold (1991); Hegarty (1992); Roussou (1994), and more recently Haegeman \& Ürögdi (2010) and Kastner (2015), to focus not on the factive presupposition per se, but rather point to the 'nominal' or 'definite' character of the types of predicates that give rise to weak island effects (building on insights from Kiparsky \& Kiparsky 1970).

Among these accounts, there are two main lines of analysis. On one type of analysis, the weak island effects receive a syntactic (Relativized Minimality) explanation: complements of verbs like deny and regret have a null operator in their left-periphery, which serve as an intervener for A-bar extraction, and additionally gives rise to the types of pragmatic "definiteness" effects associated with complements of factive and response stance verbs (see for instance Progovac 1988; Melvold 1991; Hegarty 1992; Watanabe 1993; Zubizarreta 2001; Roussou 1994, and more recently Haegeman \& Ürögdi 2010). The problem for this type of approach is that it is not built to account for the uniqueness-effects illustrated in (7)-(8) in section 1, as these are associated with the semantic content of the embedded clause.

The second type of account is primarily associated with Honcoop (1998), and has been adopted more recently in work by Kastner (2015), who provides a concrete syntactic scaffolding for Honcoop's (1998) semantic proposal. On this account, complements of factive and response stance verbs are both part of a more general class of presuppositional verbs, which embed (or, for Kastner, select) for presuppositional clauses, in the sense that they pick out a discourse referent in the common ground

2 The same is more obviously true for negative response stance verbs like doubt and deny. These may fall, though, under negative weak islands, for which other meaning-based explanations have been proposed (Rullmann 1995; Fox \& Hackl 2006; Abrusán 2011: a.o.). 
(for Kastner, such complements are additionally headed by a null D-layer). Just like the syntactic accounts discussed in the previous paragraph treat weak islands in terms of intervention effects, Honcoop treat weak islands in terms of scope effects, building on Szabolcsi \& Zwarts (1993). Honcoop's (1998) proposal is couched within the framework of Dynamic Semantics, and is motivated by the observation that the expressions that lead to scope islands also give rise to so-called inaccessibility effects, in terms of being able to introduce a discourse referent that can be picked up by cross-sentential anaphora, as illustrated in (25).

(25) Cross-sentential anaphora \& scope islands (Honcoop 1998: 4, 17)

a. John $\{$ has, *doesn't have $\}$ a car ${ }_{i}$. $_{i}$ is expensive.

b. How $i$ did, *didn't $\}$ he behave $t_{i}$ ?

Taking so-called what-for $N P_{\text {indef }}$ split constructions in Germanic as a core case of weak island sensitive expressions, Honcoop proposes to reduce the explanation of weak (scope) island effects to that of the anaphora facts: in (25a), the negative operator creates an inaccessible domain for the indefinite NP a car to dynamically bind the non-c-commanded pronoun it. The key assumption is that the mechanism that allows for this dynamic binding (Dekker's 1993 Existential Disclosure) is only available in contexts that allow cross-sentential anaphora. Honcoop's prediction is therefore that negative and other operators, which block cross-sentential anaphora (as shown in (25a)), should also give rise to weak island effects in what-for $N P_{\text {indef }}$ split constructions and other weak island sensitive expressions.

As Honcoop himself points out, however, the parallel between cross-sentential anaphora and weak islands runs into problems in the case of presuppositional attitude islands. As illustrated in (26), the verbs that give rise to inaccessible domains are not the same as those that give rise to weak island effects: there are some nonisland inducers which constitute inaccessible domains for dynamic anaphora (like think and believe), and conversely, there are island inducers which do not constitute inaccessible domains (like be happy, remember, and know):

Adapted from Honcoop (1998: 168)

John $\{*$ thought, is happy $\}$ that he saw a bird ${ }_{i}$ today. $\mathrm{It}_{i}$ was blue.

To capture the presence vs. absence of weak island effects with the two sets of verbs, Honcoop introduces an intensionalized version of Existential Disclosure, which is able to capture the lack of weak island effects with verbs like think. Crucially, this requires that $\mathrm{p}$ is introduced as a new discourse referent. Honcoop argues that the mechanism which prevents weak island effects with verbs like think is not applicable to factive and response stance verbs, as these verbs require $\mathrm{p}$ to be old information, referring back to previous discourse referents, rather than creating 
(Non-)factive (non-)islands and meaning-based approaches

new ones. Like the proposals discussed above, Honcoop (1998: 179-180) also draws an explicit parallel between the two types of attitude verbs and (in)definitness in the nominal domain.

The main problem for this type of approach, as for the syntactic accounts discussed above, is that it doesn't provide a mechanism for dealing with the type of uniqueness-effects discussed here. ${ }^{3}$ Nevertheless, we agree with the core insight of the proposals discussed here, that the discourse status of $\mathrm{p}$ matters for the weak island effect. However, rather than linking the effect to the syntactic properties of the embedded clause, or to anaphoric binding (and/or selection), we will argue that this insight can also be captured within Schwarz \& Simonenko's (2018) meaning-based account, once we adopt a broader notion of contextual entailment. This will allow us to account for both the uniqueness-effects illustrated in (8), and the observation from this and the previous section, that lexical factivity is neither necessary nor sufficient.

\section{Proposal: Contextual entailment instead of presupposition}

Taken together, the data discussed here has shown us that the factive weak island effects are both more pervasive, and at the same time less robust, than has been assumed on previous accounts. In order to capture the distribution of the weak island effects across embedding and pragmatic contexts, we argue that meaning-based approaches like Schwarz \& Simonenko (2018)'s must loosen the notion of factivity in favour of a broader notion of pragmatically or lexically triggered contextual entailment.

\subsection{Accounting for factive non-islands within the meaning-based account}

In section 3.1, we saw that factive verbs may fail to give rise to weak island effects in so-called 'evidential questions' like (16), despite being lexically + factive and +unique. This, we suggest, is not because the Answerability Condition (11) is not required to be met, but because certain factives allow for a kind of evidential use where the context does not have to entail $\mathrm{p}$, as already observed in previous work for cases where these verbs combine with declarative complements, as in (18). Hence, the interpretation we get with these evidential uses is the presupposition-less question What is the location $x$ s.t. they discovered that Caesar was killed in $x$ ?, as shown in (27):

3 As Szabolcsi (2006: 526) points out, this account also has no clear way of explaining the weak island sensitivity found with the (arguably related) cases of how and why-questions; in the sense that it's not clear why they would be assimilated to split constructions, under the Existential Disclosure approach. A similar point is also made in Abrusán (2011: fn. 3, 263). 
$\llbracket(16 a)=$ Where did they discover that Caesar was killed? $\rrbracket=$ $\left\{\lambda w\right.$. they discovered ${ }_{w}$ that Caesar was killed in the Theatre of Pompey, $\lambda \mathrm{w}$. they discovered ${ }_{w}$ that Caesar was killed in the Senate Building, $\lambda$ w. they discovered ${ }_{w}$ that Caesar was killed in the Basilica Porcia, ...

This, then, is similar to the corresponding non-factive question Where do they think that Caesar was killed?, which also lacks a presupposition (though as we saw in section 3.1, the two questions differ in terms of veridicality).

$\llbracket(20)=$ Where do they think that Caesar was killed? $\rrbracket=$

$\left\{\lambda w\right.$. they think $_{w}$ that Caesar was killed in the Theatre of Pompey,

$\lambda$ w. they think $k_{w}$ that Caesar was killed in the Senate Building,

$\lambda$ w. they think ${ }_{w}$ that Caesar was killed in the Basilica Porcia, ... $\}$

For concreteness, we can model such evidential uses either in terms of Heim's (1983) local accommodation or as a back/fore-grounded entailment, as in Simons, Beaver, Roberts \& Tonhauser (2017). ${ }^{4}$ What matters for current purposes is simply the lack of global presupposition projection in these cases. Without a global presupposition of $\mathrm{p}$, the absence of weak island effects in questions like (16), which involve factive verbs like find out and discover in +unique contexts, directly follows from the meaning-based approach. In section 2, we saw that in a question involving factivity and uniqueness (see (8a) and (9)), the two felicity conditions on questions -the Answerability Condition in (11) and the Existential Presupposition in (12)- lead to contradictory demands, so that there is no possible context set $\mathrm{c}$ that satisfies both conditions. In the case of the evidential questions in (16), however, given that no presupposition projects, the presuppositional part (c $\subseteq \operatorname{dom}(\mathrm{p})$ ) of the Answerability Condition in (11) is trivially satisfied. Thus, the only requirement imposed by the Answerability Condition is that the question has an answer $\mathrm{p}$ which is informative in c. As a result, the weakened Answerability Condition and the Existence Presupposition do not lead to contradictory demands.

Thus, with this small adjustment about our assumptions about the pragmatics of factive verbs, we capture the observation that questions involving factive verbs may escape the island-effects also in these kinds of evidential contexts, in addition to in non-unique contexts.

\subsection{Accounting for non-factive islands within the meaning-based account}

Regarding the presence of weak island effects with non-factive verbs like admit, it has been observed since Karttunen (1977) that these verbs do tend to project a fairly strong, though defeasible, not-at issue pragmatic veridical inference:

4 Another recent alternative comes from Djärv (2019), who provides an account of factivity where $\mathrm{p}$ is neither a lexical presupposition nor a backgrounded entailment. 
(Non-)factive (non-)islands and meaning-based approaches

(29) a. She didn't admit that [ $p$ Caesar was killed in the Theatre of Pompey]. $\leadsto p$

b. Did she admit that $[p$ Caesar was killed in the Theatre of Pompey]? $\sim \mathrm{p}$

This observation is also supported by experimental data from German, English, and Swedish in Djärv (2019: Ch. 3.2), showing that participants rated the positive response stance verbs accept and admit close to lexically (cognitive and emotive) factive verbs, in terms of perceived speaker commitment to $\mathrm{p}$, in both embedded and unembedded environments.

At this point, one might be tempted to suggest that verbs like accept and admit are actually just factive, an alternative which would immediately take care of the problem. However, as we saw in (24) above, there are clear differences between these verbs, and lexically factive verbs like discover, in terms of the defeasibility/cancellability of the p-inference in unembedded contexts. Instead, we follow Anand \& Hacquard (2014), who argue that verbs like admit create an illusion of factivity, stemming from the fact that they report discourse moves that the describe acceptance of $\mathrm{p}$ in the reported common ground. If the reported conversational context is taken to be representative of the actual conversational context (in the evaluation world), then "acceptance of $\mathrm{p}$ can easily bleed into the actual common ground, under the assumption that no subsequent move removed $\mathrm{p}$ from the common ground: an illusion of factivity arises whenever a reported context is taken to faithfully represent the conversational community in the world of evaluation." (p. 74-75). In (30), p projects because we conventionally take the book to be making its acknowledgement in a conversational context that includes the participants of the actual context. Crucially, however, as shown in (31), with sufficient 'epistemological distance' between the contexts, the illusion of factivity disappears:

(30) Anand \& Hacquard (2014: 74)

Does the book $\{$ acknowledge, admit, confirm $\}$ that Mary is the murderer?

$\leadsto$ Mary is the murderer

(31) Anand \& Hacquard (2014: 75)

In Ancient Greece it was widely accepted that the Earth was flat. Eratosthenes however thought that it was round. After his peers demonstrated to him that he couldn't be right, he finally \{acknowledged/admitted $\}$ that the Earth was flat. $x \rightarrow$ The Earth was flat.

We propose that it is this factive-like inference that is the cause of the weak island effects observed with these non-factive verbs. Our claim is that, as a default, questions with admit-verbs are interpreted against a context that entails p. In such cases, the question will encounter both uniqueness and a factive like-inference (see (9)-(10)), and thus necessarily violate either felicity condition in (11)-(12), as we saw in section 2 . 
Djärv and Romero

\section{Extending the scope of the theory}

The keystone of the meaning-based approach to factive islands by Schwarz \& Simonenko (2018) rests on the presence of a unique, non-iterable "gapped" property in the presuppositional core of the question, as sketched in (32). In their account, this presupposition is triggered by the factivity of the embedding attitude verb. Section 4 discussed the nature of the implication containing the "gapped" property, showing that it doesn't require a lexically factive verb: a pragmatic contextual inference with the same content suffices to create a weak island. In the present section, we will see that, besides factive verbs, other types of presupposition-triggers -e.g. again-also give rise to the same type of weak-islandhood effects.

$$
\lambda w .\left\{\lambda w^{\prime}: \mathbf{P}_{\text {unique }}(\mathrm{x})\left(\mathrm{w}^{\prime}\right) \text {. } \mathbf{S}(\mathrm{x})\left(\mathrm{w}^{\prime}\right) \mid \mathbf{R}(\mathrm{x})(\mathrm{w})\right\}
$$

We start with an iterable, non-unique property, e.g. $\left[\lambda x . \lambda w\right.$ you invited $\left.w_{w} x\right]$ in (33). This sentence allows for an underlying LF structure where the presupposition trigger again scopes over the trace of the extracted phrase, as in (33a). This results in the question meaning in (33b), asking for the person(s) x such that, after you invited $\mathrm{x}$ before $\mathrm{t}$, you invited $\mathrm{x}$ at the relevant time $\mathrm{t}$ too. Since uniqueness is not at play, no conflict arises between the Answerability Condition (11) and the Existence Presupposition (12) and the extraction is acceptable.

(33) Who did you invite again?

\section{a. LF: [CP $\mathrm{Who}_{i}$ [ [ you invited $\left.\mathbf{t}_{i}\right]$ again (at time t) ] ]}

b. $\lambda \mathrm{w} .\left\{\lambda \mathrm{w}^{\prime}\right.$ : you invited $\mathrm{w}^{\prime} \mathrm{x}$ before $\mathrm{t}$. you invited $\mathrm{w}_{w^{\prime}} \mathrm{x}$ at $\left.\mathrm{t} \mid \operatorname{person}(\mathrm{x})(\mathrm{w})\right\}$

Now consider the unique property that -following Oshima (2007)- is obtained when extracting a how-phrase, e.g. the property $\left[\lambda \mathrm{x} . \lambda \mathrm{w}\right.$ you fixed-car ${ }_{w}$ in manner $\mathrm{x}]$ in (34). A parallel structure where again scopes over the trace of how, as in LF1 in (34a), leads to ungrammaticality. This can be seen in that the resulting reading (34b) -asking for the manner $\mathrm{x}$ such that, after you fixed the car in manner $\mathrm{x}$ before $t$, you fixed the car in manner $x$ at $t$ as well- is not available. Instead, the only reading acceptable is (34d), roughly paraphrasable as 'Granted that the car was fixed before t. How did you fix it at t?'. This reading corresponds to LF2 in (34c), where, crucially, again does not have the trace of how in its scope and, thus, there is no extraction across a potential island-inducer:

(34) How did you fix the car again?

a. LF1: *? [CP $\mathrm{How}_{i}\left[\right.$ [ you fixed the car $\mathbf{t}_{i}$ ] again (at time t) ] ]

b. *? $\lambda \mathrm{w}$. $\left\{\lambda \mathrm{w}^{\prime}\right.$ : you fixed-car $w_{w^{\prime}}$ in manner $\mathrm{x}$ before $\mathrm{t}$. you fixed-car $w_{w^{\prime}}$ in manner $\mathrm{x}$ at $\mathrm{t} \mid \operatorname{manner}(\mathrm{x})(\mathrm{w})\}$ 
(Non-)factive (non-)islands and meaning-based approaches

c. LF2: $\left[{ }_{C P} \operatorname{How}_{i}\right.$ [ [ you fixed the car] again $\mathbf{t}_{i}$ (at time $\left.\left.\mathrm{t}\right)\right]$

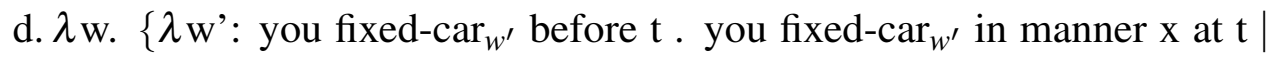
$\operatorname{manner}(\mathrm{x})(\mathrm{w})\}$

The same considerations apply when the unique "gapped" property results again following Oshima (2007) - from the extraction of why in (35). LF1 in (35a) where again scopes over the trace is ungrammatical, since the corresponding reading (35b) is unavailable. This reading can be roughly paraphrased as 'For what reason $\mathrm{x}$, after Bill came for reason $\mathrm{x}$ before $\mathrm{t}$, Bill came for reason $\mathrm{x}$ at $\mathrm{t}$ '. The only available reading is given in (35d), paraphrasable as 'Granted that Bill came before t. For what reason did he come at t?'. The latter reading follows from LF2 in (35c), where, crucially, again does not include the trace of why in its scope and, hence, no extraction out of a potential island is taking place:

Why did Bill come again?

a. LF1: * ${ }_{C P}$ Why $_{i}$ [ [ Bill came $\mathbf{t}_{i}$ ] again (at time t) ] ]

b. $* \lambda w$. $\left\{\lambda w^{\prime}\right.$ : Bill came con $_{w^{\prime}}$ for reason $\mathrm{x}$ before $\mathrm{t}$. Bill came cor $_{w^{\prime}}$ for reason $\mathrm{x}$ at $\mathrm{t} \mid \operatorname{reason}(\mathrm{x})(\mathrm{w})\}$

c. LF2: $\left[{ }_{C P} \mathrm{Why}_{i}\left[\right.\right.$ [ Bill came] again $\mathbf{t}_{i}$ (at time t)] ]

d. $\lambda \mathrm{w}$. $\left\{\lambda \mathrm{w}^{\prime}\right.$ : Bill came $w_{w^{\prime}}$ before $\mathrm{t}$. Bill came $_{w^{\prime}}$ for reason $\mathrm{x}$ at $\left.\mathrm{t} \mid \operatorname{reason}(\mathrm{x})(\mathrm{w})\right\}$

This means that extraction from the scope of the presupposition trigger again induces the same kind of selective weak island as extraction from the complement of a lexically factive verb like know. The approach by Schwarz \& Simonenko (2018), when applied to these new cases, directly derives the desired results. Regardless of what the trigger of the presupposition is, what matters in their approach is having a unique "gapped" property in the presuppositional core, which brings the Answerability Condition (11) and the Existence Presupposition (12) to conflicting requirements.

\section{Discussion}

In this paper, we have argued that what matters for the meaning-based approach to factive weak islands is contextual entailment, which is a broader notion than lexical factivity. Building on insights by accounts appealing to the discourse status of $p$, we showed that, viewed as a case of pragmatic contextual entailment, we can capture the weak island-insensitivity of factives like discover in evidential questions and the weak island-sensitivity of non-factives like admit, within the meaning-based approach of Schwarz \& Simonenko (2018). Additionally, we have shown that a meaning-based approach like theirs can also be extended to cases where the weak island effect is linked to presupposition triggers other than factive predicates. 
Djärv and Romero

\section{References}

Abrusán, Márta. 2011. Presuppositional and negative islands: A semantic account. Natural Language Semantics 19(3). 257-321. doi:10.1007/s11050-010-9064-4. Abusch, Dorit. 2010. Presupposition Triggering from Alternatives. Journal of Semantics 27. 37-80. doi:10.1093/jos/ffp009. (Also cited as 2009).

Anand, Pranav \& Valentine Hacquard. 2014. Factivity, belief and discourse. In Luka Crnič \& Uli Sauerland (eds.), The Art and Craft of Semantics: A Festschrift for Irene Heim, 69-90. MIT Working Papers in Linguistics.

Cattell, Ray. 1978. The source of interrogative adverbs. Language 54. 61-77. doi: $10.2307 / 412999$.

Dayal, Veneeta Srivastav. 1996. Locality in WH quantification: Questions and relative clauses in Hindi. Dordrecht: Kluwer Acadmic Publishers.

Dekker, Paul. 1993. Existential disclosure. Linguistics and Philosophy 16. 561-587. doi:10.1007/bf00985434.

Djärv, Kajsa. 2019. Factive and assertive attitude reports: The University of Pennsylvania $\mathrm{PhD}$ dissertation.

Fox, Danny \& Martin Hackl. 2006. The universal density of measurement. Linguistics and Philosophy 29(5). 537-586. doi:10.1007/s10988-006-9004-4.

Haegeman, Liliane \& Barbara Ürögdi. 2010. Referential CPs and DPs: An operator movement account. Theoretical Linguistics 36. 111-152. doi:10.1515/thli.2010.015.

Hamblin, Charles L. 1973. Questions in montague grammar. Foundations of language 10(1). 41-53. doi:10.1016/b978-0-12-545850-4.50014-5.

Hegarty, Michael. 1992. Adjunct extraction without traces. In Dawn Bates (ed.), West Coast Conference on Formal Linguistics (WCCFL), vol. 10, 209-222. Stanford: CSLI Publications.

Heim, Irene. 1983. On the projection problem for presuppositions. In Daniel P. Flickinger (ed.), West Coast Conference on Formal Linguistics (WCCFL), vol. 2, 114-125. Stanford University, Stanford, California: CSLI Publications.

Honcoop, Martin. 1998. Dynamic excursions on weak islands: Leiden University $\mathrm{PhD}$ dissertation.

Huang, C.-T. James. 1982. Logical relations in Chinese and the theory of grammar: Massachusetts Institute of Technology $\mathrm{PhD}$ dissertation.

Karttunen, Lauri. 1977. Syntax and semantics of questions. Linguistics and philosophy 1(1). 3-44. doi:10.1007/978-94-009-9509-3_6.

Kastner, Itamar. 2015. Factivity mirrors interpretation: The selectional requirements of presuppositional verbs. Lingua 164. 156-188. doi:10.1016/j.lingua.2015.06.004.

Kiparsky, Paul \& Carol Kiparsky. 1970. Fact. In Michael Bierwisch \& Karl Erich 
(Non-)factive (non-)islands and meaning-based approaches

Heidolph (eds.), Progress in Linguistics, 143-173. The Hague: Mouton.

Lasnik, Howard \& Mamoru Saito. 1984. On the nature of proper government. Linguistic Inquiry 15. 235-289.

Lasnik, Howard \& Mamoru Saito. 1994. Move alpha: Conditions on its application and output 22. MIT press.

Melvold, Janis. 1991. Factivity and definiteness. MIT working papers in linguistics 15. 97-117.

Oshima, David Y. 2007. On factive islands: pragmatic anomaly vs. pragmatic infelicity. New Frontiers in Artificial Intelligence 147-161. doi:10.1007/978-3540-69902-6_14.

Progovac, Ljiljana. 1988. A binding-theoretic approach to polarity sensitivity: University of Southern California, Los Angeles PhD dissertation.

Ross, Haj. 1984. Inner islands. In Berkeley Linguistics Society (BLS), vol. 10, 258-265.

Roussou, Anna. 1994. The syntax of complementisers: University College London $\mathrm{PhD}$ dissertation.

Rullmann, Hotze. 1995. Maximality in the semantics of wh-constructions: University of Massachusetts Amherst PhD dissertation.

Schlenker, Phillipe. 2008. Be articulate: A pragmatic theory of presupposition projection. Theoretical Linguistics 34(3). 157-212. doi:10.1515/thli.2008.013.

Schwarz, Bernhard, David Y. Oshima \& Alexandra Simonenko. 2019. Factive islands from necessary blocking. In Katherine Blake, Forrest Davis, Kaelyn Lamp \& Joseph Rhyne (eds.), Semantics and Linguistic Theory (SALT), vol. 29, 529-548.

Schwarz, Bernhard \& Alexandra Simonenko. 2018. Factive islands and meaningdriven unacceptability. Natural Language Semantics 26(3-4). 253-279. doi:10.1007/s11050-018-9146-2.

Simons, Mandy. 2007. Observations on embedding verbs, evidentiality, and presupposition. Lingua 117. 1034-1056. doi:10.1016/j.lingua.2006.05.006.

Simons, Mandy, David Beaver, Craige Roberts \& Judith Tonhauser. 2017. The best question: Explaining the projection behavior of factives. Discourse Processes 54(3). 187-206. doi:10.1080/0163853x.2016.1150660.

Szabolcsi, Anna. 2006. Strong vs. weak islands. The Blackwell companion to syntax 479-531.

Szabolcsi, Anna \& Frans Zwarts. 1993. Weak islands and an algebraic semantics for scope taking. Natural Language Semantics 1(3). 235-284. doi:10.1007/bf00263545.

Szabolcsi, Anna \& Frans Zwarts. 1997. Weak islands and an algebraic semantics for scope taking. In Anna Szabolcsi (ed.), Ways of Scope Taking, 217-262. Dordrecht: Kluwer. 
Theiler, Nadine. 2021. An epistemic bridge for presuppostion projection in questions. In J. Rhyne et al. (ed.), Semantics and Linguistic Theory (SALT), vol. 30, 252272.

Urmson, James Opie. 1952. Parenthetical verbs. Mind 61. 480-496. doi:10.1093/mind/lxi.244.480.

Watanabe, Akira. 1993. Larsonian CP recursion, factive complements, and selection. In North East Linguistic Society (NELS), vol. 23, 523-537.

Zubizarreta, Maria Luisa. 2001. The constraint on preverbal subjects in romance interrogatives: A minimality effect. In A. Hulk \& J.-Y. Pollock (eds.), Subject Inversion in Romance and the Theory of Universal Grammar., 183-204. Oxford: Oxford University Press.

Kajsa Djärv

University of Konstanz

kdjarv@sas.upenn.edu
Maribel Romero

University of Konstanz

maribel.romero@uni-konstanz.de 